In: Comprehensive Analytical Chemistry, Elsevier, 2007, Volume 49,

Electrochemical Sensor Analysis, Pages e169-e176

\title{
"Procedure 24 Construction of an enzyme-containing microelectrode array and use for detection of low levels of pesticides"
}

Frank Davis ${ }^{\mathrm{a}}$, Karen A. Law ${ }^{\mathrm{a}}$, Anthony P. F. Turner ${ }^{\mathrm{a}}$ and Seamus P. J. Higson*, ${ }^{\mathrm{a}}$

${ }^{\text {a }}$ Cranfield University at Silsoe, Barton Rd, Silsoe, MK45 4DT, UK., Phone: +44

(1525) 863453, Fax: +44 (1525) 863533, Email: s.p.j.higson@cranfield.ac.uk

\section{Objectives}

(a) To construct a microelectrode array based on a screen printed substrate. (b) To utilise the microelectrode array to form an array of enzyme-containing electrodes (c) To test the electrode response to thiocholine (d) To expose the array to low levels of pesticide and measure the relative response to thiocholine following inhibition.

\section{Materials and instruments}

Sodium phosphate monobasic [S 9638], sodium phosphate dibasic [S 0876], sodium chloride [S 7653], acetylcholinesterase from Electrophorus electricus (Type V-S) [C 2888], potassium chloride [P 3911], 1,2-diaminobenzenedihydrochloride [P 1526], paraoxon (o,o-diethyl $o$-4-nitrophenyl phosphate) [D 9286], ferrocene carboxylic acid [106887], aniline [A 9880] and acetylthiocholine chloride [A 5751] were purchased from the Sigma Chemical Company (Dorset, UK). Screen-printed transducers were purchased from Gwent Electronic Materials Ltd. (Gwent, Wales, UK). These electrode assemblies comprised a working electrode based on carbon ink doped with cobalt phthalocyanine, an on board reference electrode $(\mathrm{Ag} / \mathrm{AgCl})$ and counter electrode (platinum) (see Fig. 1).

Electrochemical deposition of poly(1,2-diaminobenzene) and polyaniline, cyclic voltammetry and amperometry were performed using a Sycopel Scientific AEW2 portable electrochemical workstation interfaced to a PC running ECProg3 software (Sycopel Scientific Ltd., Tyne and Wear, England). Sonochemical ablation of poly(diaminobenzene) films was performed at a frequency of $25 \mathrm{kHz}$ using an Ultrawave SFE590 sonic bath (Ultrawave Ltd., Cardiff, Wales). Scanning electron micrographs of bare, polydiaminobenzene coated, sonicated and AChE-modified CoPC electrodes were obtained using a Jeol 6300 scanning electron microscope. 
Enzyme immobilisation was performed within a custom-made, low-volume ( $3 \mathrm{ml})$ PTFE cell, which housed working, reference and counter electrodes. All water used was purified with a ELGA Purelab UHQ purifier.

\section{3. (Bio)sensor preparation}

Prepare a $5 \mathrm{mM}$ solution of 1,2-diaminobenzenedihydrochloride in phosphate buffered saline, pH $7.4\left(5.28 \times 10^{-2} \mathrm{M} \mathrm{Na}_{2} \mathrm{HPO}_{4} ; 1.3 \times 10^{-2} \mathrm{M} \mathrm{NaH}_{2} \mathrm{PO}_{4} ; 5.1 \times 10^{-3}\right.$ $\mathrm{M} \mathrm{NaCl})$. Connect the electrode assembly, place into this solution and electropolymerise the 1,2-diaminobenzene dihydrochloride onto the carbon/CoPC SPEs by sequentially cycling the working electrodes between the potentials of 0 and $+800 \mathrm{mV}$ versus $\mathrm{Ag} / \mathrm{AgCl}$ for 100 cycles at a scan rate of $50 \mathrm{mV} \mathrm{s}^{-1}$. Dry the electrodes at room temperature for approximately $20 \mathrm{~min}$ before rinsing with deionised water to remove unreacted monomer from the electrode surface. Polydiaminobenzene is a non-conducting polymer that progressively insulates surfaces upon which it is polymerised with a self-limiting process to provide thin insulating covering polymer films of approximately $50 \mathrm{~nm}$ thickness [1]. The electrochemical profile of this reaction is shown (Fig. 2) and clearly demonstrates progressive insulation of the surface by the deposition of poly(1,2-diaminobenzene).

Sonochemical ablation of poly(1,2diaminobenzene) modified insulated SPEs is the next stage. Support the modified electrodes upright in a beaker containing distilled, deionised water which must then be subsequently positioned into the ultrasonic bath. Sonicate the electrodes for $10 \mathrm{~s}$ at a frequency of $25 \mathrm{kHz}$.

It is possible to use cyclic voltammetry in the presence of ferrocene carboxylic acid to confirm the presence of micro-electrodes due to the typical sigmoidal-shaped profile produced [2] (Fig. 3). Twenty different sensors comprising micro-electrode arrays formed by this technique were analysed for reproducibility. This analysis can be performed by holding the sensors at a potential of $+100 \mathrm{mV}$ for $60 \mathrm{~s}$ and recording the current responses during 50-60 s. By comparing 20 sensors, it was found that these sensors containing micro-electrode arrays had an R.S.D. between sensors of $7 \%$.

Firstly prepare a solution of $0.1 \mathrm{M}$ aniline in acetate buffer, $\mathrm{pH}$ 5.0 (0.4 M sodium acetate, $0.4 \mathrm{M}$ acetic acid and $0.4 \mathrm{M}$ sodium chloride). Also perpare a solution of acetylcholinesterase $\left(100 \mathrm{U} \mathrm{mL}^{-1}\right)$ in distilled water. Mix $1 \mathrm{~mL}$ of the enzyme preparation with the same volume of aniline solution in the PTFE cell immediately prior to electropolymerisation. Aniline containing acetylcholinesterase can be polymerised onto sonicated polydiaminobenzene coated SPEs by sequentially cycling for $10 \mathrm{~min}$ between -200 and $+800 \mathrm{mV}$ versus $\mathrm{Ag} / \mathrm{AgCl}$ at $50 \mathrm{mV} \mathrm{s}^{-1}$. As the aniline polymerises at the exposed microelectrode elements, the polymer forms mushroomlike protrusions that extend outwards from the electrode surface and within which the acetylcholinesterase becomes entrapped. After polymerisation, the electrodes must be immediately submerged in $\mathrm{pH} 7.4$ phosphate buffer at $4{ }^{\circ} \mathrm{C}$ to prevent enzyme denaturation and stored at $4{ }^{\circ} \mathrm{C}$ prior to use.

Scanning electron micrographs of bare, polydiaminobenzene coated, sonicated and AChE-modified CoPC electrodes were obtained using a Jeol 6300 scanning electron microscope. They clearly show formation of "mushroom"-like protrusions of polyaniline. 


\section{4. (Bio)sensor calibration}

Firstly prepare a stock solution of $1 \mathrm{mM}$ paraoxon in PBS, $\mathrm{pH} 7.4$, and dilute accordingly in PBS to yield standard solutions of concentrations from $1 \times 10^{-8}$ to $1 \times$ $10^{-17} \mathrm{M}$. Serial dilutions must be used to attain the very low levels of paraoxon concentration. Ultra pure water must also be used as the very low levels of pesticide detection mean the effet of impurities in water must be minimised. Obtain a baseline response by lowering the AChE-modified SPE into $20 \mathrm{ml}$ of phosphate buffer $(\mathrm{pH}$ 7.4) and measuring the current versus $\mathrm{Ag} / \mathrm{AgCl}$ reference/counter electrode, with stirring, at a working potential of $+100 \mathrm{mV}$. After a steady baseline response is achieved (usually approximately $30 \mathrm{~min}$ ), inject acetylthiocholine chloride substrate into the cell to produce a final concentration of $2 \mathrm{mM}$. The amperometric response must then be measured and recorded. Remove the working electrode immediately from the cell and rinse with phosphate buffer ( $\mathrm{pH}$ 7.4) before pipetting a known concentration of paraoxon solution $(20 \mu \mathrm{L})$ onto the working area. Incubate the electrode at room temperature for 20 min before rinsing thoroughly with further buffer.

The electrode should then be immediately immersed into fresh PBS, pH $7.4(20 \mathrm{~mL})$ and upon reaching a steady baseline (approximately $30 \mathrm{~min}$ as before), the amperometric response to $2 \mathrm{mM}$ acetylthiocholine chloride must again be determined as before. Repeat for paraoxon levels within the concentration range $10^{-17}$ to $10^{-8} \mathrm{M}$. We found baseline responses did not appear to drift at any point during these experiments and after the addition of acetylthiocholine chloride a steady state response was obtained within minutes. Measurements should be made in triplicate. All published responses were reported as the mean of triplicate measurements with the error bars corresponding to \pm 1 standard deviation. Control experiments can be performed by injecting phosphate buffer ( $\mathrm{pH}$ 7.4) containing no acetylthiocholine chloride and also by following the exact procedure above using denatured acetylcholinesterase.

Please note that all amperometric results shown in this paper were taken as a cumulative signal of micro-electrodes (i.e. a micro-electrode array) and not from individual micro-electrodes.

\section{Discussion}

\subsection{Scanning Electron Microscopy}

Representative voltammograms for the polymerisation of aniline/AChE at sonochemically fabricated templates showed that aniline may be polymerised under acidic conditions to form a conducting polymer that allows for the continuous deposition of the polymer with co-entrapped enzyme. Scanning electron micrographs [4] of the surface of these sensors clearly shows the presence of these enzymecontaining polyaniline protrusions (also contained within the accompanying paper). The average number of micro-electrodes produced on these sensors can be estimated by a simple population per given area counting method. Since each protrusion represents the site of a single micro-electrode, by counting the number of enzyme/polyaniline protrusions, the micro-electrode pore density can be estimated. In this particular case, $\sim 70,000 \mathrm{~cm}^{-2}$ micro-electrodes were produced. 
5.2 Enzyme sensor responses to choline

Enzyme micro-electrode arrays, on exposure to differing concentrations of the substrate acetylthiocholine chloride (Fig. 4), demonstrate that above concentrations of $1 \mathrm{mM}$, responses tend towards a plateau. For this reason, all sensory inhibitory responses to pesticides were recorded in the presence of $2 \mathrm{mM}$ acetylcholine. It should be noted that since sensor responses are recorded in the order of hundreds of $\mathrm{nA}$, it is clear that some current amplification must be operating to achieve currents of this order of magnitude. This is particularly obvious when working electrodes of 0.5 $\mathrm{cm}^{2}$ were used, which only present a combined micro-electrode array area of approximately $1 \times 10^{-5} \mathrm{~cm}^{-2}$ per screen printed electrode (if the total number of micro-electrodes that can be produced by this technique is $2 \times 10^{5} \mathrm{~cm}-2[2,3,4]$.

5.3 Detection of paraoxon

Amperometric responses, Fig. 5, show a calibration curve for paraoxon inhibition of AChE-modified CoPC electrodes for paraoxon concentrations from $1 \times 10^{-17}$ to $1 \times$ $10^{-8} \mathrm{M}$.

\section{Selected literature}

1. S. Myler, S. Eaton, S. P. J. Higson, Anal. Chim. Acta 357 (1997) 55-61.

2. A. C. Barton, S. D. Collyer, F. Davis, D. D. Gornall, K. A. Law, E. C. D. Lawrence, D. W. Mills, S. Myler, J. A. Pritchard, M. Thompson M, S. P. J. Higson, Biosens. Bioelec., 20 (2004) 328-337.

3. J. A. Pritchard, K. A. Law, A. Vakurov, P. A. Millner, S. P. J. Higson, Biosens. Bioelec., 20 (2004) 765-772.

4. K. A. Law, S. P. J. Higson, Biosens. Bioelec. 20 (2005) 1914-1924. 


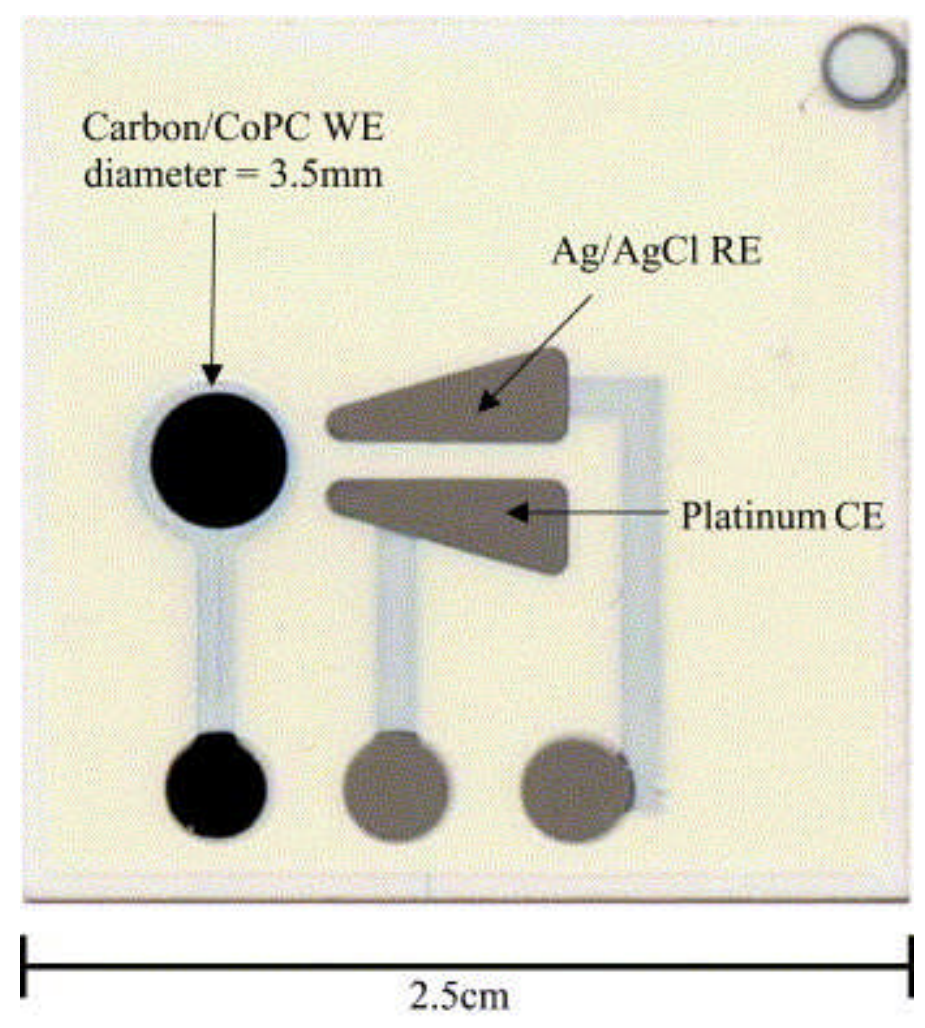

Fig. 1. Screen-printed CoPC-doped electrode.

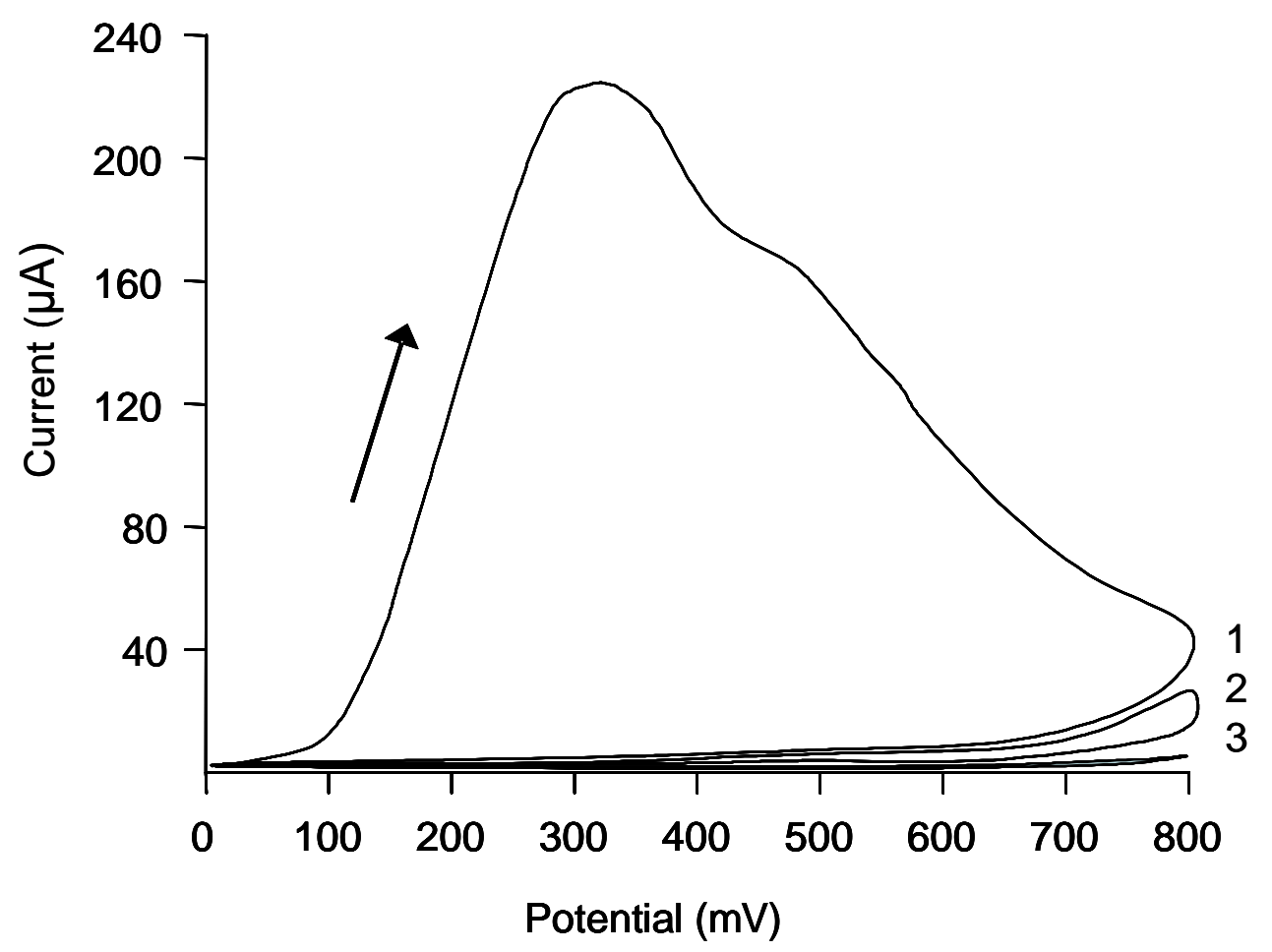

Fig. 2. A typical cyclic voltammogram showing progressive insulation of the carbon electrode by polydiaminobenzene deposition. 


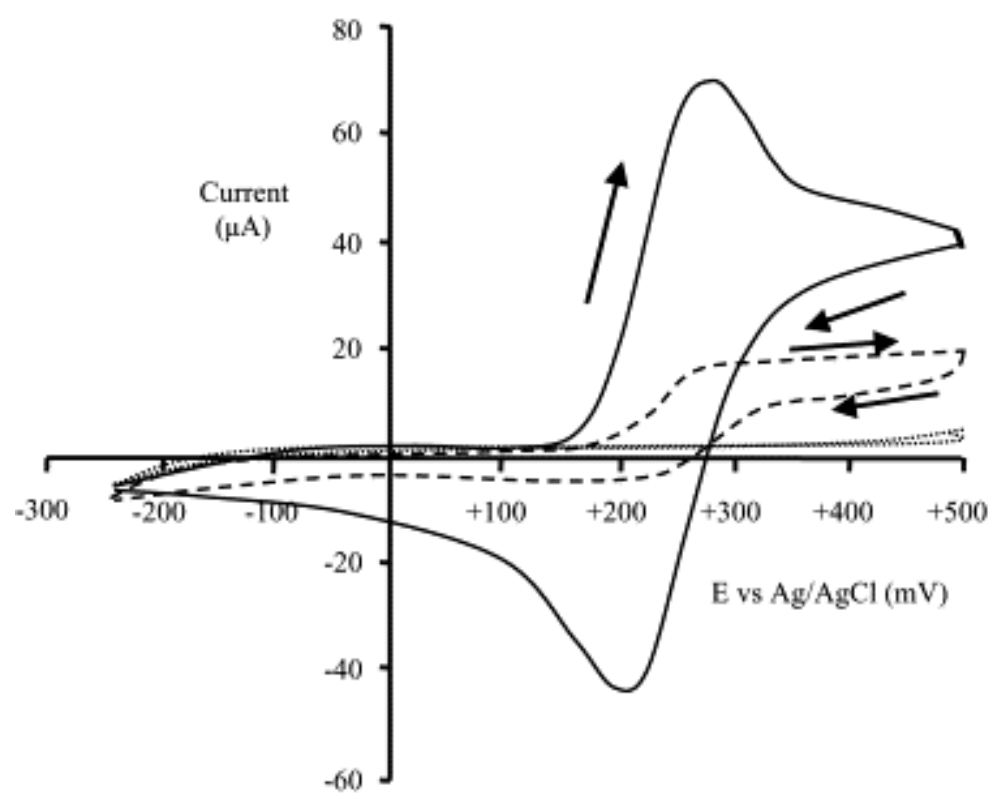

Fig. 3. Cyclic voltammogram of ferrocene carboxylic acid at a bare carbon electrode (一), a poly(o-phenylenediamine)-coated working electrode ( ... ) and at sonicated poly(o-phenylenediamine)-coated carbon working electrode (- - -).
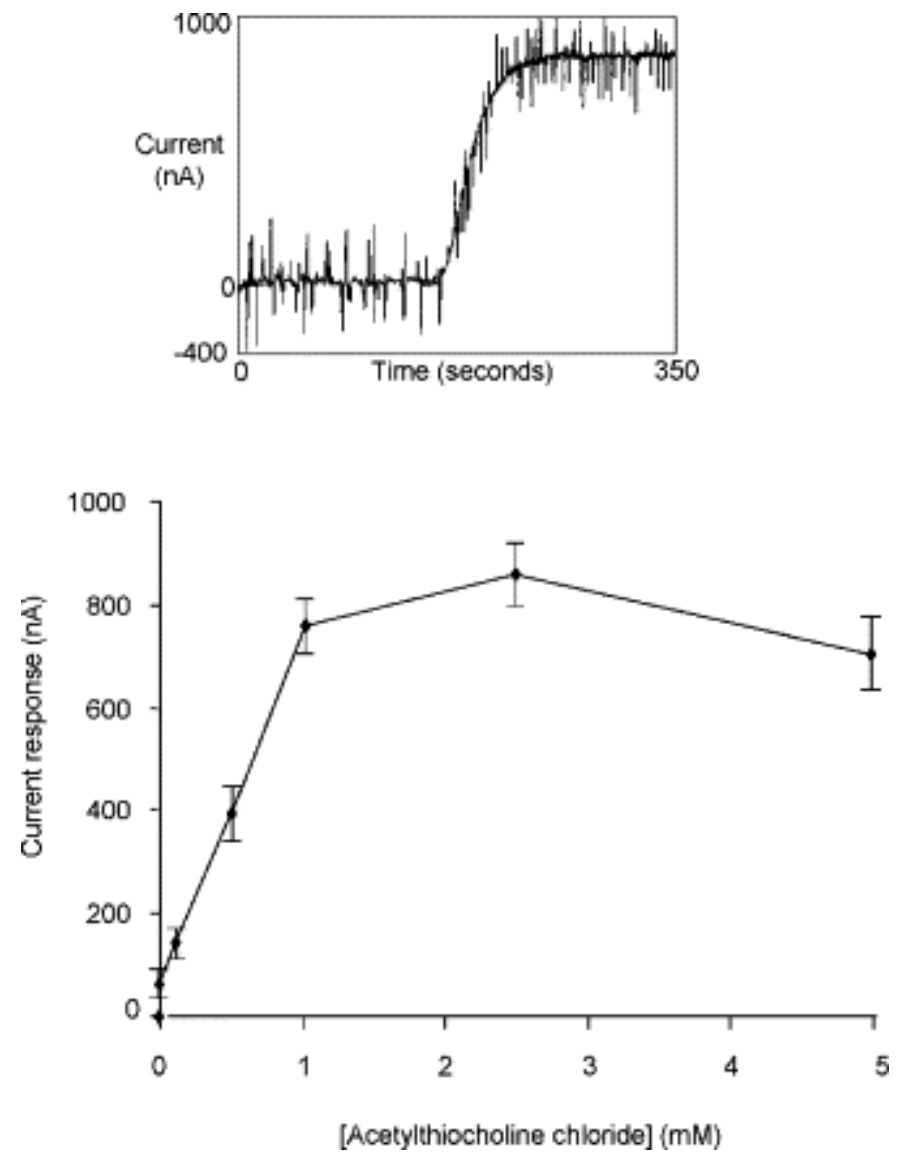

Fig. 4. Amperometric enzyme microelectrode array responses to acetylcholine between the concentration range $0-5 \mathrm{mM}(\mathrm{n}=3$, S.D. $< \pm 10 \%)$. Inset show a typical current transient response for an AChE electrode when exposed to $2.5 \mathrm{mM}$ acetylthiocholine chloride. 


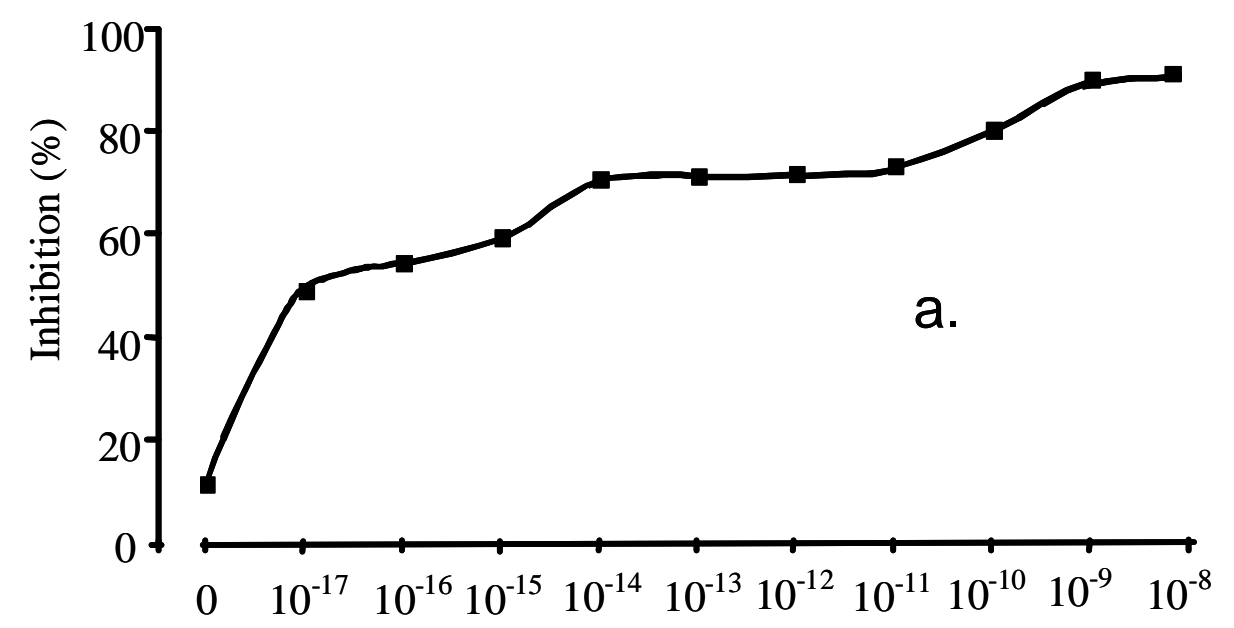

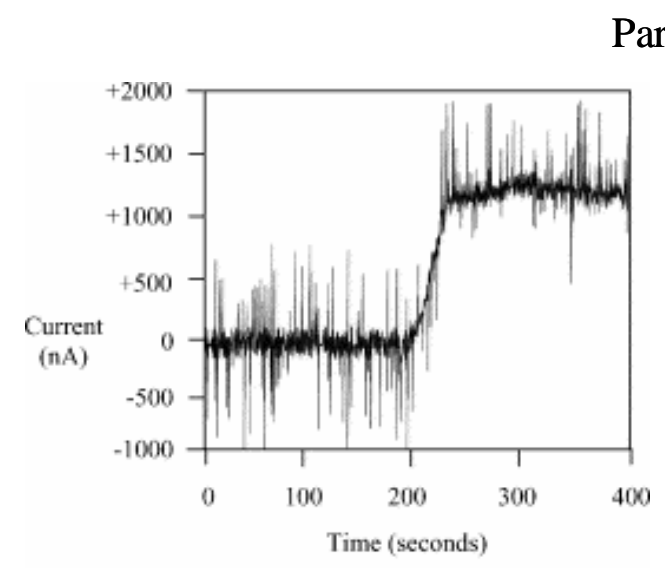

b.

Paraoxon (M)

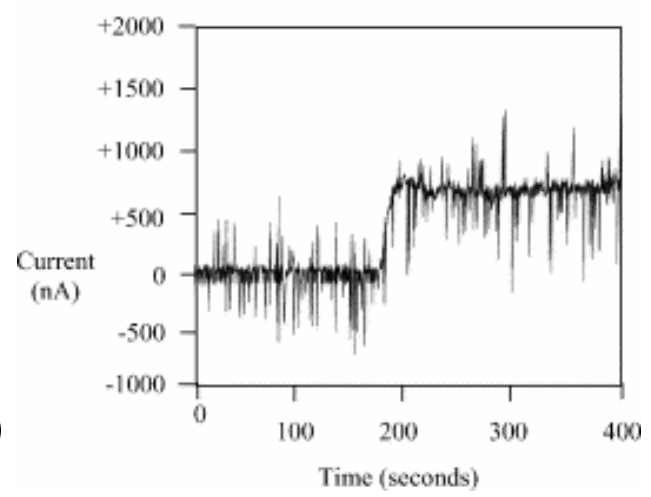

C.

Fig. 5a. Calibration curve for paraoxon inhibition of acetylcholinesterase-modified CoPC electrodes for paraoxon concentrations between $10^{-8}$ and $10^{-17} \mathrm{M}$ using a concentration of $2 \mathrm{mM}$ acetylthiocholine chloride $(\mathrm{n}=3$, S.D. $< \pm 11 \%)$. Insets show a typical current transient response for an AChE-modified electrode to $2 \mathrm{mM}$ acetylthiocholine chloride, before (b) and after (c) the addition of $1 \times 10-17 \mathrm{M}$ paraoxon. 